\title{
CÁRITAS E A FORMAÇÃO DA CIDADANIA UMA RETOMADA HISTÓRICA
}

Telmo Adams*

SÍNTESE - O artigo pretende analisar como a Cáritas Brasileira, uma instituição social do campo religioso católico, vem rompendo com um modelo assistencialista de ação social. Que fatores têm estimulado esse processo de ruptura criando condições para a instauração de uma proposta hegemônica de formação para a cidadania, consagrando gradativamente um modelo organizativo-participativo com opção pela transformação social? Num primeiro momento, situaremos historicamente o surgimento da Cáritas no contexto dos anos 50, quando se definiam os primeiros passos da estruturação do Serviço Social no Brasil. Em seguida, buscaremos demonstrar como se deu a passagem de uma visão de ajustamento social, para uma perspectiva de transformação social; e como essa nova proposta levou as instâncias da Cáritas a priorizar a participação em instrumentos de luta por políticas públicas construtoras de cidadania.

PALAVRAS-CHAVE - formação, cidadania, Cáritas.
ABSTRACT - The article intends to analyze how Brazilian Cáritas, a social institution of religious Catholic character, has been moving away from a supportive model of social action. Which factors have stimulated this process of rupture, by creating conditions for the instauration of a hegemonic proposal of formation for citizenship, and by gradually consecrating an organizationalparticipative model that chooses social transformation? First, we will locate the appearance of Cáritas historically in the context of the 1950s, when the first steps toward structuring Social Work in Brazil were being taken. Next, we will seek to demonstrate how the passage from a vision of social adjustment to a perspective of social transformation took place. We will also try to demonstrate how this new proposal has taken Cáritas to prioritize the participation in means of fight for public policies that build citizenship.

KEY WORDS - formation, citizenship, Cáritas.

\section{1-O surgimento do Serviço Social}

As instituições são produtos de contextos sócio-históricos, ao mesmo tempo que se constituem em instrumentos de produção social, contribuindo para a manutenção ou a transformação das estruturas sociais. O Serviço Social (a partir da década de 40) e a Cáritas (década de 50) nasceram e evoluíram em meio a essa complexa teia de relações, que é a vida em sociedade.

* Graduado em Filosofia (1981), com especialização em Pastoral Popular (1985) e em Cooperativismo (1987). Mestrando em Serviço Social na Pontifícia Universidade Católica do Rio Grande do Sul (PUCRS). 
Numa sociedade com profundas marcas de dominação, herdadas de um processo de colonização espoliador, é consenso reconhecer que o Serviço Social nasceu para amenizar tais chagas sociais. ${ }^{1}$ Assim, na década de 40 , durante o Estado Novo, um tipo de serviço social começa a existir e gradativamente se constitui como espaço profissional, com a clara tarefa de controlar os setores urbanos emergentes incorporando algumas reivindicações populares. Fortemente ligado ao laicato da Igreja Católica, o Serviço Social constitui-se em instrumento de legitimação social. Sua base teórica era a doutrina social da Igreja, que se caracterizava pela visão tomista de ajustamento social. Portanto, à assistência social cabia colaborar com o poder público para integrar a população pobre à sociedade, dentro de uma visão de harmonia e equilíbrio social. Nesse mesmo contexto surge a Cáritas Brasileira.

\section{1 - A constituição de um espaço de reprodução social}

A Cáritas foi fundada pela Igreja Católica, em 1950, na Europa, para socorrer as vítimas das duas guerras mundiais. Num segundo momento, coube a ela articular todos os organismos católicos nacionais e internacionais que tinham por finalidade "promover a caridade, a assistência, a justiça social e o desenvolvimento no mundo". ${ }^{2}$

No Brasil, a Cáritas foi fundada pela Conferência Nacional dos Bispos do Brasil, em 1956. Inicialmente, dentro do contexto da época, coube-lhe coordenar e administrar o programa de alimentos ${ }^{3}$ da Catholic Relief Services - CRS (Cáritas da Igreja Católica dos EUA). Esse programa desenvolvia-se dentro da concepção de Desenvolvimento de Comunidade ${ }^{4}$ que trazia, em seu bojo, a mesma visão hegemônica de harmonia e equilíbrio da sociedade, onde a comunidade era o centro. A intervenção consistia em integrar indivíduos à sociedade. ${ }^{5}$ Nesse contexto, a Cáritas se legitimou na Igreja e na sociedade e foi reconhecida como distribuidora de mantimentos. Aliás, ainda hoje ela carrega essa "marca".

\footnotetext{
Martinelli, 1989, p. 57.
}

2. Secretaria do Estado do Vaticano, pronunciamento oficial, 1997. In: Cánitas Paroquial - um estudo sobre o serviço da caridade. Porto Alegre, 1980, p. 7. (mimeo)

3 Inicialmente este programa era chamado de Alimentos para a Paz e posteriormente de Alimentos para o Desenvolvimento. "Os excedentes agrícolas norte-americanos, usados inicialmente para ajuda aos refugiados da Segunda Guerra Mundial, foram depois canalizados para as regiões subdesenvolvidas" (Cáritas RS. Cáritas Paroquiais - um estudo sobre o serviço da caridade. Porto Alegre, 1980, mimeo).

4 Em nivel de governo, estratégia mais abrangente da oNU e de outros organismos internacionais, foi elaborada no sentido de traçar uma política mais ampla para o Brasil. Esse trabalho foi elaborado por uma Comissão Mista Brasil - EUA e pelo Grupo Misto BNDE-CEPAL que resultou no Plano de Metas 1956/61 (Mantega, 1984, p. 72-73, em Economia politica brasileira - o nacionaldesenvolvimentismo). Essa análise histórica está igualmente detalhada em artigo de Maria Ozanira da Silva e Silva: "O serviço social na conjuntura brasileira: demandas e respostas", p. 80-81, 1994.

5 Essa visão de "integração social" era sintetizada por setores da sociologia lideradas por Durkheim, bem como por algumas enciiclicas que davam orientações sociais: Doutrina Social da Igreja. A sociedade em princípio era boa. O problema eram os indivíduos desajustados. 
Essa primeira fase, que se estendeu até o início dos anos 60, foi um periodo marcado por práticas assistencialistas e, portanto, uma ação reprodutora de manutenção da sociedade. Contudo, em meio a relações contraditórias de disputa entre as diferentes forças do campo do poder, começou a se fortalecer um trabalho de educação popular. Surgiram movimentos sociais de caráter popular de toda ordem. Com o aval da instituição maior da Igreja, surgiram o Movimento de Educação de Base (MEB), as Comunidades Eclesiais de Base (CEBS) ${ }^{0}$ e as diversas pastorais sociais para enfrentarem problemas especificos (indígenas, terra, operários, criança, saúde...). Justamente durante o complicado período da ditadura militar surgiram as condições favoráveis para as maiores rupturas nas práticas sociais de agentes de Igreja e assistentes sociais que tomaram posição em favor da defesa da cidadania e da luta pela democratização da sociedade brasileira. Contudo, a Cáritas, enquanto proposta institucional, chegou à perspectiva da transformação social um pouco mais tarde, a partir da década de $80 .^{7}$

\section{2 - Rompimento com um modelo assistencialista}

Através da visão sintética exposta até aqui, podemos destacar alguns fatores geradores de rupturas nas linhas de ação da Cáritas Brasileira, de modo especial no Estado do Rio Grande do Sul: a) a suspensão do programa de alimentos (1963), o que possibilitou a busca de novas formas de trabalho social; b) a admissão de profissionais assistentes sociais e elaboração dos primeiros planos de atividade (periodo 1964-1969) que garantem uma ação mais qualificada; c) o Concílio Vaticano II e seus desdobramentos, através das conferências episcopais, ${ }^{8}$ foram motivação e apelo para apoiar e despertar novas iniciativas de trabalho social; d) o II Congresso da Cáritas do Rio Grande do Sul - Promoção Humana à Luz de Puebla (1980), que trouxe experiências e propostas concretas para fortalecer uma nova perspectiva de assistência social como instrumento de formação para a cidadania;

6 Os movimentos de renovação já existentes na Igreja Católica, especialmente desde os anos 50, influenciaram o Concilio Vaticano II (1964-1967) que por sua vez consagrou e fortaleceu uma mudança radical da Igreja ser na sociedade. $\mathrm{Na}$ visão do Concílio, a Igreja deve ser um serviço à sociedade, contribuindo na construção da Justiça e da Paz. Os desdobramentos desse evento foram as Conferências Latino-Americanas de Bispos (Medellin, 1968; Puebla, 1979) que representaram uma concretização das orientações do Vaticano II para a América Latina.

7 Após uma avaliação critica, a própria Cáritas reconheceu quatro grandes fases em quatro épocas referenciais (não estanques). $1^{a}$ fase: 1956/1963 - ênfase na ação assistencial, distribuição de ahmentos, articulação de obras sociais católicas, $2^{a}$ fase: 1964/1969 - ênfase na chamada promoção humana: cursos profissionalizantes e cursos de afazeres de caráter mais doméstico, como cozinha, higiene, costura, pintura..., $3^{\text {å }}$ fase: 1970/1980 - continuação da promoção humana, com ênfase na pastora! ce conjunto, especialmente na organização de base (CEBS e pastorais sociais), $4^{\text {a }}$ fase: $1980 / . .$. ènfase na organização comunitária/grupos, articulação com outros setores da sociedade, busca de uma nova metodologia baseada no método de educação popular de Paulo Freire. Essa proposta de superação de uma prática assistencialista e paternalista teve seu reforço nas orientações nos documentos do Concílio Vaticano II, nas conclusões das Conferências dos Bispos LatinoAmericanos de Medellin e Puebla.

8 Cf. Conferência de Medellin, 1968, “A Cáritas, que é um organismo da Igreja integrado dentro da Pastoral de Conjunto, não será somente uma instituição de beneficência, mas deve inserir-se mais operativamente no processo de desenvolvimento da América Latina, como uma instituição verdadeiramente promocional." 
e) o III Congresso da Cáritas do Rio Grande do Sul - Fé cristã e compromisso social (1984), que fortaleceu a proposta do modelo da caridade libertadora; f) o capital humano: até o final da década de 70 predominou uma prática social tradicional de "integração social"; já a partir de 1980 a entrada de profissionais assistentes sociais em cargos de direção da Cáritas, apoiados numa metodologia participativa e nas afirmações atualizadas do magistério da Igreja, tiveram uma ação decisiva no sentido de fazer do trabalho social um instrumento de organização comunitária e de formação para a cidadania.

\section{2 - A Cáritas e a formação para a cidadania}

No Rio Grande do Sul, desde o final da década de 70, os dirigentes do Secretariado Regional têm estimulado as equipes localizadas nas 14 dioceses a buscarem uma nova metodologia de ação. Um dos instrumentos para garantir a superação de um modelo assistencialista, especialmente a partir dos anos 80, foi o grande investimento em cursos de formação de agentes de Cáritas, com vistas a prepará-los dentro de uma metodologia participativa. Fortificou-se, assim, o chamado modelo da Caridade Libertadora inspirado em práticas já existentes e orientações oficiais da Igreja. Além da denúncia das injustiças causadoras do empobrecimento, esta cumpreensão metodológica tem estimulado empreendimentos e processos de organização dos empobrecidos, estimulando a que eles mesmos lutem pela sua emancipação ou libertação integral. ${ }^{9}$ Propõe a formação para a cidadania solidária, onde os excluídos se tornem agentes políticos individuais e coletivos, na conquista de direitos negados. Nessa perspećtiva, são estimuladas iniciativas de formação para a cidadania em torno de práticas alternativas nas áreas do trabalho, saúde, educação, moradia. Enfim, em todas a lutas voltadas aos direitos sociais e econômicos. ${ }^{10}$

Contudo, dentro da Cáritas estão reproduzidas as contradições da Igreja. Devido a isso, em muitos locais, a sua ação esteve e continua dependente e aprisionada por uma orientação tradicional dos dirigentes da Igreja. O social é uma trama complexa de conflitos. Mas a visão hegemônica no campo católico é a de medo do conflito, vendo-o, inclusive, como pecaminoso porque quebra a harmonia das relações de fraternidade. Em decorrência, continua-se reforçando uma prática assistencialista de adaptação dos indivíduos à sociedade. Não se trata aqui de aprofundar essa questão que é relevante e constituinte do campo religioso, onde a disputa de interesses está presente, mesmo que de forma velada. De outra parte, é

9 A concepção de Libertação Integral marca a Encíclica Populorum Progressio, de Paulo VI que resume o objetivo da evangelização da Igreja numa libertação que atinja o "homem todo e todos os homens", isto é, que transforme a pessoa em todas as dimensões da vida. A mesma concepção foi assumida pela Teologia da Libertação, dentro do contexto de "injustiça institucionalizada" na América Latina e no Caribe.

10 Desde 1986 a Cáritas do Rio Grande do Sul atua com uma linha de ação denominada construção de altemativas de vida, tendo já apoiado mais de 1.100 projetos sociais e de geração de renda. Nesta perspectiva ela lidera, nos últimos anos, um grupo de instituições que atuam com altemativas, constituindo um fórum de economia popular solidária. Está em fase de conclusão a $2^{\text {a }}$ pesquisa sobre essas experiências com um rico material de análise e reflexão sobre tal trabalho social no Estado. 
no contraponto da contradição que se criam as condições para as rupturas. É esse processo dinâmico, especialmente dos últimos 10 anos, que faz com que a Cáritas venha desempenhando uma inegável contribuição na formação da cidadania. A ação direta de muitos agentes na organização de grupos de base em comunidades de periferia, a articulação com movimentos e organizações populares, o engajamento em conselhos paritários municipais e estaduais em vista da luta por políticas públicas, são alguns exemplos de práticas que garantem a legitimidade e atualidade da instituição.

Sem abandonar sua missão permanente de animação da solidariedade comunitária, isto é, a ação nas situações de emergência (de caráter social ou as causadas por catástrofes da natureza), a Cáritas decidiu incluir nas suas prioridades, a atuação junto às políticas públicas. Desde 1995, participa do Comitê Interinstitucional de Articulação da Assistência Social no Estado do Rio Grande do Sul (CIAS), criado com o objetivo de implementar a Lei Orgânica de Assistência Social (LOAS), homologada em 1993. A Cáritas foi eleita e assumiu uma vaga no Conselho Estadual de Assistência Social, ${ }^{11}$ instalado em agosto de 1996. A atuação do Conselho foi marcada pela forte disputa entre os representantes da sociedade civil - que queriam assumir o papel deliberativo - e o governo que, por decreto, the determinou um caráter apenas apreciativo, desrespeitando a lei maior. ${ }^{12}$

$\mathrm{Na}$ participação do Conselho de Assistência Social, a Cáritas buscou concretizar seu compromisso com a nova realidade: "assistência social enquanto direito do cidadão e dever do Estado". ${ }^{13}$ Após dois anos, a avaliação dos resultados dessa dinâmica mostrou uma série de contradições. De um lado, a participação da Cáritas garantiu um avanço no processo de formação e participação política, na medida em que favoreceu a apropriação de um grande número de informações e saberes relacionados ao campo do poder. Além disso, os conselheiros representantes da sociedade civil conseguiram exercer um certo controle social sobre as ações do governo. Mas, por outro lado, constatou-se que, em grande parte, o Conselho serviu simplesmente para legitimar uma ação governamental clientelista.

Enfim, essa é uma dimensão nova da prática da Cáritas que vem ampliar os espaços de luta na conquista de políticas públicas que fortaleçam a cidadania. $O$ desenvolvimento de seminários e debates sobre a questão tem sido importante na formação para a cidadania. Percebe-se o quanto o habitus ${ }^{14}$ político, seja dos go-

11 São oito membros eleitos: três das entidades prestadoras de serviço (Cáritas RS, Lions Clube, SESI), dois membros das entidades de trabalhadores do setor (CRESS, SENALBA) e ttrês membros de entidades de usuários (Fraternidade Cristã de Deficientes Físicos, Federação Rio-Grandense de Entidades de Deficientes Físicos e Conselho Estadual de Juventude Rural do RS). A FAMURS (Federação das Associações dos Municípios do Estado do Rio Grande do Sul) é membro nato, ocupando uma vaga da sociedade civil. Além desses, são mais nove representantes indicados de órgãos do governo. Todos os titulares contam com um suplente.

12 Ainda, antes da oficialização do Conselho Estadual, o CIAS ingressou com uma ação de inconstitucionalidade no Ministério Público que, até junho de 1998, ainda não se havia pronunciado. Na prática, o governo não reconheceu o Conselho como instância definidora das politicas de assistência social para o Estado.

13 Lei Orgânica de Assistência Social. In: Coletânea de leis - CREss, Porto Alegre, 1996, p. 49.

14 BOURDIEU, P. 1992: p. 97: "habitus: um sistema socialmente constituído de disposições estruturadas e estruturantes que é adquirido pela prática e constantemente orientado pelas funções práticas". 
vernantes como das instituições e povo em geral, traz as marcas históricas de dominação. Os conselhos, quando não são submissos às decisões do executivo, são vistos como perigosos, desnecessários, um estorvo para a prática do tradicional clientelismo político. O exercício da democracia plena, e não apenas a formalidade da delegação pelo voto, ainda é uma conquista a ser feita.

\section{Conchusão}

A Cáritas no Brasil nasceu num contexto em que a concepção de assistência social era a de executar as políticas governamentais de "ajustamento social". Foram pelo menos 20 anos de uma prática caracterizada como assistencialista ou geradora de dependência. Entre os fatores de ruptura desse modelo certamente conseguimos levantar alguns dos que mais contribuíram para a evolução de um modelo de trabalho social gerador de cidadania. Talvez a suspensão do programa de alimentos (1963) tenha sido o fator externo decisivo para a instituição redimensionar sua razão de existir em função da transformação social.

A passagem para um novo modelo hegemônico aconteceu em meio a um Iongo e contraditório processo de disputa de interesses e necessidade de legitimidade para a Igreja e a sociedade. Nessa perspectiva, as atuais prioridades de ação podem ser resumidas na formação para a cidadania, onde a prática social traz necessariamente um cunho educativo. É aí que está justamente a diferença entre um modelo assistencialista de trabalho social e outro modelo gerador de cidadania com co-responsabilidade e solidariedade social.

Por último, constatamos que a participação em conselhos paritários, embora seu caráter conflitivo e ainda dependente dos governantes (executivos), agrega-se como mais um fator necessário para garantir o avanço nas políticas públicas. Assim, além da ação nos microespaços (famílias, grupos, comunidades), atinge-se igualmente os macroespaços (setores públicos mais amplos e instituições estatais). Para a Cáritas, os dois espaços de intervenção articulados são reconhecidos como essenciais para construção da cidadania dos excluídos, com vistas à transformação social.

\section{Referências bibliográficas}

MARTINELLI, Maria Lúcia. Serviço Social - identidade e alienação. São Paulo: Cortez, 1989. PIERRE Bourdieu. Razões práticas: sobre a teoria da ação. São Paulo: Papirus, 1995.

CÁRTTAS RS. Promoção humana à luz de Puebla - Anais do II Congresso de Cáritas do Rio Grande do Sul. Porto Alegre, 12-14 de setembro de 1980 - PUCRS.

_. Cáritas paroquiais - um estudo sobre o serviço da caridade. Porto Alegre, 1980.

Fé cristã e compromisso social - Anais do III Congresso Estadual de Cáritas. Porto Alegre, outubro de 1984. 